\section{Control of breathing: effects of analgesic, anaesthetic and neuro- muscular blocking drugs}

Richard L. Knill MD FRCPC
"Breuthing is truly a strange phenomenon of life, caught midway between the conscious and unconscious, and peculiarly sensitive to both ..."

D.W. Richards (1953)

Throughout the history of anaesthesia, a major cause of morbidity and mortality has been failure of ventilation. In the past, this was usually attributed to anaesthetics causing excessive "central depression." In recent years, it has become evident that many anaesthetic agents are not simply non-specific central depressants of breathing but rather have discrete and sometimes potent actions on various mechanisms of breathing control. Knowledge of these specific actions can be helpful to the clinician in anticipating the particular circumstances of anaesthesia and the postanaesthetic period in which ventilation is most likely to be seriously impaired.

The purposc of this presentation is to provide an up-to-date review of the important effects of commonly used anaesthetic, analgesic and ncuromuscular blocking drugs on resting ventilation and mechanisms of breathing control in humans. These effects will be considered with reference to a simple model.

\section{Model of breathing control}

The system which regulates breathing consists of threc basic elements: inputs, controllers and effectors ${ }^{l}$ (see Figure). There are two separate controllers: (1) a primary

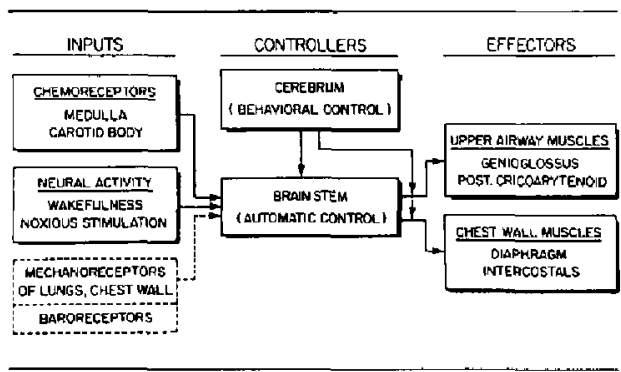

FIGURE Schematic representation of ventilatory control system. brain stem controller concerned with automatic (or involuntary) breathing and (2) a secondary cerebral controller which superimposes behavioural (or voluntary) influences on ventilation. The brain stem controller receives and integrates various inputs and then sends impulses through motor neurons to the effectors or ventilatory muscles. The cerebral controller directs the same effectors but its inputs are complex and poorly understood.

The inputs to the brain stem controller provide the drive for automatic breathing. Since this controller is fundamentally concerned with maintaining oxygenation and acid/hase homeostasis, its principle inputs arise from chemoreceptors which sense variables of oxygen and acid/base balance. Two sets of chemoreceptors perform this function: one in the medulla sensitive to brain $\mathrm{PCO}_{2}-\left[\mathrm{H}^{+}\right]$activity; the other in the carotid bodies reactive to the $\mathrm{PO}_{2}$ and $\mathrm{PCO}_{2}-\left[\mathrm{H}^{+}\right]$of arterial blood. The effective input of each appears at thresbolds of $\mathrm{PO}_{2}$ and/or $\mathrm{PCO}_{2}-\left[\mathrm{H}^{+}\right]$and then increases in relation to reductions of $\mathrm{PO}_{2}$ and/or increments of $\mathrm{PCO}_{2}-\left[\mathrm{H}^{+}\right]$. A second type of input to the automatic contraller arises from the nonspecific neural activity or "traffic" in the brain stem reticular formation. Although not as well characterized, this input likely mediates the effects of wakefulness and noxious stimulation on breathing. ${ }^{2}$ The wakefulnessrelated input adds only slightly to normal resting chemoreceptor drive, but becomes critically important when the chemoreceptor input is severely impaired. If, for example, chemoreceptor drive is abolished - as with a low $\mathrm{PCO}_{2}$ and high $\mathrm{PO}_{2}$ - an input related to wakefulness can take over and maintain breathing at about two-thirds normal values. ${ }^{3}$ Other types of input originate with the mechanoreceptors of the lungs and chest wall and the baroreceptors of the cardiovascular system. These are not pertinent to this presentation

The effectors of the system are the two groups of muscles that achicve ventilation: (1) the muscles of the

Department of Anaesthesia, University Hospital, P.O. Box 5339, Postal Station A, London, Ontario, N6A 5A5. 
upper airway (c.g., genioglossus and posterior cricoarytenoids) and (2) the muscles of the chest wall (diaphragm, intercostals and accessories). Each group displays two types of activity: (1) intermittent or phasic and (2) continuous or tonic. 4.5 The phasic activity generates inspiration. That of the upper airway muscles enlarges the airway with each breath; that of the chcst wall muscles acts to inflate the lungs. The tonic activity performs certain "postural" functions. That of the genioglossus helps to keep the airway open between breaths ${ }^{4}$ and that of the diaphragm helps maintain the end-expiratory lung volume (i.e., FRC) in the supine position. ${ }^{5}$

\section{Sedatives/hypnotics/tranquillizers}

This varied group of CNS depressants, which includes the barbiturates, phenothiazines and benzodiazepines, has no important effect on resting breathing if given in doses that produce only sectation or light sleep. However, these agents do impair certain mechanisms of breathing control and as a result may affect breathing in vulnerable patient groups. Sedative/hypnotics can reduce the ventilatory responses to chemoreceptor stimuli, i.e., added $\mathrm{CO}_{2}{ }^{6}$ andor hypoxaemia. ${ }^{7}$ In patients who have chronic ventilatory failure (e.g., with COPD) and thus reduced responses to chemoreceptor stimuli related to disease, the added depressive effect of these drugs can be sufficicnt to worsen ventilatory failure and precipitate a respiratory crisis $^{8}$ - especially in association with loss of wakefulness or sleep. 9 Sedative/hypnotics also suppress the normal tone of the effector muscles of the upper airway. ${ }^{10}$ In patients with the obstructive sleep apnoea syndrome and an anatomical predisposition to upper airway obstruction, this relaxing effect is believed to be responsible for an increase in the number and severity of apnoeas during sleep. ${ }^{11}$

\section{Narcotic analgesics}

All narcotic analgesics (morphine, meperidine, fentanyl, etc.) are potent ventilatory depressants. Equi-analgesic doses of individual agents have quantitatively similar effects. In the usual analgesic doses, they depress breathing primarily by reducing the breathing rate and increase $\mathrm{PaCO}_{2} 3$ or $4 \mathrm{mmHg}$. These effects increase with dose until, at the point of loss of consciousness or "sleep," periodic breathing or apnoea occurs. Those agents that possess both agonist and antagonist activity (e.g., nalbuphine) display a ceiling of ventilatory depression at moderate doses. However, this is of little therapeutic advantage since their analgesic effect is limited too. ${ }^{12}$

Narcotics also alter the mechanisms of breathing control. Accompanying the changes in resting breathing and $\mathrm{PaCO}_{2}$ are dose-related reductions of the responses to chemoreceptor stimuli, both added $\mathrm{CO}_{2}$ and hypoxaemia. ${ }^{13}$ Thus, patients who have ventilatory failure and preexisting impaired responses to these stimuli are also more sensitive to narcotic effect. ${ }^{8}$

As responses to chemoreceptor stimuli are obtunded by a narcotic, ventilation becomes more dependent upon the input of wakefulness. Thus, loss of wakefulness - as with natural nonREM sleep - appears to potentiate narcotic induced ventilatory depression. ${ }^{14}$ The magnitude of this effect is modest at an ordinary analgesic dose, ${ }^{14}$ but can be dramatic in the presence of a larger dose, in which case loss of wakefulness or sleep may precipitate severe hypopnoea or apnoea. ${ }^{15}$ Such sleep induced apnoea can be reversed by arousing the patient and prompting him to breathe, j.e., by making use of the wakefulness and/or behavioural control mechanisms.

Any drug or drug combination which abolishes wakefulness has the potential to greatly exaggerate narcotic depression of breathing. For example, a larger dose of narcotic by itself may reduce brcathing only modestly. However, the addition of a small dose of sedative or tranquillizer which, with the narcotic, induces sleep can result in marked hypopnoea or apnoea. ${ }^{15}$ Thus when a narcotic and a tranquillizer are given together, as in neuroleptanalgesia, the dose of narcotic should be judicious and limited to that which is necessary to relieve pain (see below). Anaesthetizing doses of volatile anaesthetics also potentiate narcotic-induced ventilatory depression, such that even a relatively small dose of narcotic given during anaesthesia may cause severe hypoventilation or apnoea.

Noxious stimulation or pain increases the brain stem neural activity and effectively antagonizes the depression of ventilation associated with analgesic doses of narcotic. When using a narcotic to treat acute pain, one can virtually always administer it to the point of pain relief without concern for depressed breathing, regardless of the absolute dose required. This important point is too often forgotten in clinical practice.

Certain ventilatory effects of narcotic pertain to particular methods of administration. Rapid intravenous administration of a moderate to large dose can induce muscle spasm and rigidity of the chest wall to an extent that severely limits ventilation. ${ }^{16} \mathrm{~N}_{2} \mathrm{O}$ potentiates this effect and neuromuscular blockade effectively abolishes it. Epidural or subarachnoid administration of a relatively small dose of water-soluble narcotic (e.g., morphine) occasionally causes profound ventilatory depression which is delayed and apparently due to slow transport of morphine in the spinal CSF to the brain stem. ${ }^{17}$ Old age, respiratory disease and/or concomitant parenteral narcotic predispose to this effect. ${ }^{17}$ Chronic pain and/or narcotic tolerance may be protective. 


\section{Inhalational and intravenous anaesthetics}

The modern halogenated anaesthetics (halothane, isoflurane and enflurane) are also potent ventilatory depressants, but only when given in doses that produce loss of wakefulness and anaesthesia. At such doses, they reduce ventilation and tidal volume, increase breathing frequency and elevate $\mathrm{PaCO}_{2}$ - all in proportion to anaesthetic depth. The magnitude of hypoventilation varies considerably amongst equipotent doses of individual agents. At 1.0 MAC, halothane increases the average $\mathrm{PaCO}_{2}$ value to about $45 \mathrm{mmHg}$ while isoflurane increases it to $50 \mathrm{mmHg}$ and enflurane to over $65 \mathrm{mmHg}$ (making enflurane in oxygen unacceptable for spontaneous breathing). Contrary to popular expectation, depression of ventilation docs not increase with anaesthetic duration but rather decreases, in a kind of "adaptation."18 Surgical stimulation usually counteracts depression somewhat, reducing the $\mathrm{PaCO}_{2}$ about $5 \mathrm{mmHg}{ }^{19}$

Halogenated agents have several important actions on the mechanisms of breathing control.

First, they obtund responses to all chemoreceptor stimuli, ${ }^{19-21}$ independent of surgical stimulation. ${ }^{22}$ At anaesthetic doses, the slope of the response to added $\mathrm{CO}_{2}$ is depressed in a dose-related fashion - more or less in parallel with the changes in resting ventilation and $\mathrm{PaCO}_{2} .{ }^{19}$ Thus, patients with pre-existing impaired $\mathrm{CO}_{2}$ responsiveness, such as those with COPD, hypoventilate more during anaesthesia. ${ }^{20}$ This insensitivity to added $\mathrm{CO}_{2}$ during anaesthesia is the rationale for avoiding rebreathing in all spontaneously breathing patients since rebreathing increases the $\mathrm{CO}_{2}$ level much more when the $\mathrm{CO}_{2}$ response slope is reduced.

More severely affected are the reactions to hypoxaemia and to added $\left[\mathrm{H}^{+}\right]$a or metabolic acidaemia. Anaesthetic doses of halogenated agents completely abolish these responses such that ventilation is unaffected by either the oxygen tension or the acidity of the blood. ${ }^{21}$ Subanacsthetic doses markedly suppress them. ${ }^{21}$ Accordingly, those patients who depend upon the input of hypoxaemia or acidaemia to sustain ventilation (e.g., the COPD patient who has lost his sensitivity to $\mathrm{CO}_{2}$ or the patient with acute metabolic acidaemia requiring hyperventilation to defend $\left[\mathrm{H}^{+}\right]$) will breathe inadequately during and tollowing anaesthesia. Further, if acute hypoxaemia or metabolic acidaemia develop during or after anaesthesia, neither ventilatory compensation nor signs of respiratory distress appear.

Second, anaesthesia abolishes wakefulness and thereby renders ventilation completely dependent upon chemoreceptor input. ${ }^{3 *}$ In the case of the halogenated anaesthetics, chemoreceptor input relates solely to $\mathrm{CO}_{2}{ }^{2 \mathrm{~L}}$ Thus any factor during halogenated hydrocarbon anaesthesia which removes the $\mathrm{CO}_{2}$ stimulus (passive hyperventila- tion) or completely suppresses $\mathrm{CO}_{2}$ responsiveness (e.g., sufficient narcotic) abolishes all ventilatory activity and results in apnoea. These factors are made use of in instituting "controlled apnoca" for controlled ventilation.

This dependence on $\mathrm{CO}_{2}$-related input can give rise to a particular hazard during early recovery from anaesthesia in which controlled ventilation has been employed and conditions for "controlled apnoea" continue to exist, i.e., (1) the $\mathrm{PCO}_{2}$ level remains below its stimulating threshold and/or (2) $\mathrm{CO}_{2}$ responsiveness remains markedly impaired. A drowsy but awake patient may breathe adequately in these circumstances (due to the input of wakcfulness) but loss of wakefulness can precipitate severe hypopnoea or apnoea. Since wakefulness cannot be assured throughout the recovery period $\dagger$ and since early postanaesthetic levels of halogenated agent continue to render $\mathrm{CO}_{2}$ the only reliable chemoreceptor stimulus, ${ }^{21}$ continuous breathing during recovery must be considered to be still completely dependent upon $\mathrm{CO}_{2}$. Accordingly, at the end of anaesthesia involving controlled ventilation, both a stimulating level of $\mathrm{CO}_{2}$ and an adequate $\mathrm{CO}_{2}$ response must be provided for the recovery period. The presence of wakefulness and ventilation during wakefulness does not guarantee adequate breathing throughout the recovery period.

Third, the halogenated agents cause a preferential depression of certain functions of the effector system. In anaesthetic doses, they markedly suppress the activity of upper airway muscles of the tongue, predisposing to airway obstruction. This action is potent and evident at even subanaesthetic doses ${ }^{23}$ They also preferentially depress intercostal muscle activity and the tonic activity of the diaphragm at end-expiration, ${ }^{24.25}$ The selective loss of intercostal activity reduces the thoracic or rib cage contribution to spontaneous ventilation. ${ }^{24}$ The relaxation of the diaphragm at end-expiration, together with the loss of intercostal activity, is likely the principal factor responsible for the reduced end-expiratory volume (FRC) during anaesthesia (with either spontaneous or controlled ventilation). ${ }^{5}$ The reduced FRC undoubtedly underlies the microatelectasis, pulmonary shunting and impairment of oxygen uptake associated with anaesthesia. ${ }^{25}$

The importance of these various effects on effector muscle activity depends at least in part upon the structural and mechanical characteristics of the ventilatory system.

*The addition of noxious stimulation during anaesthesia adds to chemoreceptor drive ${ }^{22}$ and may reduce the threshold of chemoreceptor input, but does not alter the basic dependence of ventilation upon this input.

$\dagger$ Knill RL, Moote CA, Skinner MI, Rose EA, Lim G. The early post anaesthetic state is primarily light NREM sleep (unpublished observations). 
For example, compared to a patient with normal uirwuy anatomy, an obese patient who has excessive fat about the upper airway is more susceptible to airway obstruction from loss of upper airway muscle activity. Similarly, an obese patient with added fat weighing upon the abdomen and chest wall suffers a greater reduction of FRC and a more severe impaiment of oxygenation from loss of diaphragm tone.

The intravenous barbiturate anaesthetics (thiopentone methohexitone) have similar effects on breathing and the breathing control system except they do not cause a preferential loss of the response to hypoxaemia. Ketamine and nitrous oxide $\left(\mathrm{N}_{2} \mathrm{O}\right)$ are unique in having no effect on resting breathing in typical clinical doses. Including these latter agents in an anacsthetic mixture - and thereby decreasing the dose of other agents - can substantiaily reduce overall ventilatory depression. Thus, while enflurane 1.0 MAC alone causes an unacceptable degree of ventilatory depression, a 1.0 MAC mixture of enflurane and $\mathrm{N}_{2} \mathrm{O} 70$ per cent permits adequate sportaneous breathing. ${ }^{26}$

\section{Neuromuscular blocking drugs}

The ventilatory effects of the neuromuscular blocking agents (succinylcholine, tubocurarine, pancuronium, ctc.) result solely from their actions on the neturomuscular junctions of effector muscles. Their effect on individual muscle groups varies considerably. Amongst the muscles of the chest wall, the expiratory abdominal muscles and intercostals are the most sensitive, the inspiratory intercostals somewhat less so and the diaphragm least of all. ${ }^{27,28}$ At typical clinical doses of pancuronium, expiratory force is abolished but the diaphragm is only slightly impaired. ${ }^{29}$

The effector muscles which are the most readily compromised by the neuromuscular blocking agents are those of the upper airway. With increasing doses of tubocurarine, the carliest clinically detectable ventilatory effect is obstruction of the upper airway, ${ }^{30}$ Upper airway resistance increases ${ }^{31}$ and inspiratory flow decrease ${ }^{28}$ before there are important reductions of vital capacity or chest wall muscle strength. This is sometimes due to an inability to clear (i.e., swallow) secretions but more often due to soft tissue collapse - no doubt the result of weakened muscles of the pharynx, tongue and/or jaw. Thus, in managing neuromuscular blockade and its recovery, one must be attentive not only to the ventilatory muscles of the chest wall but in particular to those which maintain the airway.

\section{Conclusion}

Analgesic, anaesthetic and neuromuscular blocking drugs interfere with the ventilatory system in several discrete and specific ways. Awareness of their various actions improves clinical rationale for the safe management of ventilation in the peri-anaesthetic period.

\section{References}

1 Berger AI, Mitchell $R A$, Severinghaus $J W$. Regulation of respiration. N Engl J Med 1977; 297: 92-7, 138-43, 194-200,

2 Orem $/ M$. Central neural interactions between steep and breathing. In: Saunders NA, Sultivan CE (Eds). Sleep and Breathing. New York: Marcel Dekker, 1984; 91-135.

3 Fink BR, Hanks EC, Ngai SH, Papper EM. Central regulation of respiration during ancsthesia and wakefulness. Ann NY Acad Sci 1963; 109: 892-9.

4 Harper RM, Sauerland EK. The role of the tongue in sleep apnea. In: Guilleminault C, Dement WC (Eds). Sleep Apnea Syndromes. New York: Alan R. Liss, 1978; 219-34.

5 Muller N, Volgyesi $G$, Becker $L, B r y a n M H$, Bryan $A C$. Diaphragmatic muscle tone. J Appl Physiol 1979; 47: 279-84.

6 Caichlove RFH, Kafer ER. The effects of diazepam on the ventilatory response to carbon dioxide and on steadystate gas exchange. Anesthesiology 1971; 34: 9-13.

7 Hirshman CA, McCullough RE, Cohen PJ, Weil JV. Effect of pentobarbilone on hypoxic ventilatory drive in man: preliminary study. Br J Anaesth 1975; 47: 963-8.

8 Wilson RH, Hoseth W, Dempsey ME, Respiratory Acidosis. Am J Med 1954; 17; 464-70.

9 Gold MI, Reichenberg S, Freeman E. Respiratory depression in the sedated bronchitic patient: rapid version of the $\mathrm{CO}_{2}$ response curve. Anesthesiology 1969; 30: 492-9.

10 Bonora $M$, St.John $W M$, Bledsoe TA. Differential elevation by protriptyline and depression by diazepam of upper airway respiratory mator activity. Am Rev Respir Dis 1985; 131: $41-5$

11 Dolly $F R$, Block AV. Effect of furazepam on sleepdisordered breathing and noctumal oxygen desaturation in asymptomatic subjects. Am J Med 1982; 73: 239-43.

12 Gai TJ, Difazio CA, Moscichi $J$. Analgesic and respiratory depressant activity of nalbuphine: a comparison with morphine. Anesthesiology 1982; 57: 367-74.

13 Weil JV, Mc Cullough RE, Kline JS, Sodal IE. Diminished ventilatory response to hypoxia and hypercapnia after morphine in normal man. N Engl I Med 1975; 292: 1103-6.

14 Knill RL, Moote CA, Skinner MI, Rose EA, Lok PYK. Morphine-induced ventilatory depression is potentiated by non-REM sleep. Can J Anzesth 1987; 34: S101-2.

15 Severinghaus $J W$. Ventilation and anesthesia - dangerous interactions. In: Mushin WW, Severinghaus JW, Tiengo M, Gorini S (Eds). Physiological Basis of Anaesthesiology, Padua Piccin Medical Books, 1975; 201-19.

16 Comstock MK, Carter JG, Moyers JR, Stevens WC. 
Rigidity and hyperearbia associated with high dose fentanyl induction of anesthesia. Anesth Analg 1981; 60:362-3.

17 Gustafsson $L L$, Schildt B, Jacobsen $K$. Adverse effects of extradural and intrathecal opiatcs: report of a nationwide survey in Sweden. Br J Anaesth 1982; 54: 479-86.

18 Fourcade $H E$, Larson CP Jr, Hickey $R F$, Bahlman $S H$, Eger EI II. Effects of time on ventilation during halothane and cyclopropane anesthesia. Anesthesiology 1972; 36: 83-8.

19 Munson ES, Larson CP Jr, Babad AA, Regan MI, Buechel $D R$, Eger EI II. The effects of halothane, fluroxene and cyclopropane on ventilation: a comparative study in man. Anesthesiology 1956; 27: 716-28.

20 Pietak S, Weenig CS, Hickey RF, Fairley HB, Ancsthetic effects on ventilation in patients with chronic obstructive pulmonary disease. Anesthesiology 1975; 42: 160-6.

21 Knill $R L$, Clement $J L$. Ventilatory responses to acute metabolic acidemia in humans awake, sedated, and anesthetized with halothane. Anesthesiology 1985; 62: 745-53.

$22 \mathrm{Lam} A M$, Clement $J \mathbf{L}, K$ nill $R L$. Surgical stimulation does not enhance ventilatory chemoreflexes during enflurane anaesthesia in man. Can Anaesth Soc J 1980; 27: 22-8.

23 Hwang JC, St John WM, Bartlett D Jr. Respiratoryrelated hypoglossal nerve activity: influence of anesthetics. J Appl Physiol 1983; 55: 785-92.

24 Tusiewicz $K$, Bryan AC, Froese $A B$. Contributions of changing rib cage-diaphragm interactions to the ventiatory depression of halothane anesthesia. Anesthesiology 1977, 47: 327-37.

25 Hedenstierna $G$, Tokics $L$, Strandberg A, Lundguist $H$, Brismar $B$. Correlation of gas exchange impairment to development of atelectasis during anaesthesia and muscle paralysis. Acta Anaesthesiol Scand 1986; 30: 183-91.

26 Lam AM, Clement JL, Chung DC, Knill RL. Respiratory effects of nitrous oxide during enflurane anesthesia in humans. Anesthesiology 1982; 56: 298-303.

27 De Troyer A, Bastenier J, Delhez L. Function of respiratory muscles during partial curarization in humans. J Appl Physiol 1980; 49: 1049-56.

28 Gal TJ. Arora NS. Respiratory mechanics in supine subjects during progressive partial curarization.J Appl Physio 1982; 52: 57-63.

29 Donati F, Artzaka C, Bevan DR. Potency of pancuronium at the diaphragm and the adductor pollicis muscle in humans. Anesthesiology 1986; 65: 1-5.

30 Cash PT, Hoeksrra CS. Preliminary curarization in electric convulsive shock therapy. Psychiatric Quarterley 1943; $17: 20-34$.

31 Dodgson BG, Knill RL, Clement JL. Curare increases upper airway resistance while reducing ventilatory muscle strength. Can Anaesth Soc J 1981; 28: 505-6. 